\title{
COMPUTATIONAL STUDY OF INTERSTELLAR GLYCINE FORMATION OCCURRING AT RADICAL SURFACES OF WATER-ICE DUST PARTICLES
}

\author{
Albert Rimola $^{1}$, Mariona Sodupe $^{1}$, and Piero Ugliengo $^{2}$ \\ ${ }^{1}$ Departament de Química, Universitat Autònoma de Barcelona, 08193 Bellaterra, Spain; albert.rimola@uab.cat \\ ${ }^{2}$ Dipartimento di Chimica, NIS Centre of Excellence and INSTM (Materials and Technology National Consortium), \\ UdR Torino, Università di Torino, Via P. Giuria 7, 10125 Torino, Italy \\ Received 2012 February 24; accepted 2012 April 23; published 2012 July 2
}

\begin{abstract}
Glycine is the simplest amino acid, and due to the significant astrobiological implications that suppose its detection, the search for it in the interstellar medium (ISM), meteorites, and comets is intensively investigated. In the present work, quantum mechanical calculations based on density functional theory have been used to model the glycine formation on water-ice clusters present in the ISM. The removal of either one $\mathrm{H}$ atom or one electron from the water-ice cluster has been considered to simulate the effect of photolytic radiation and of ionizing particles, respectively, which lead to the formation of $\mathrm{OH}^{\bullet}$ radical and $\mathrm{H}_{3} \mathrm{O}^{+}$surface defects. The coupling of incoming $\mathrm{CO}$ molecules with the surface $\mathrm{OH}^{\bullet}$ radicals on the ice clusters yields the formation of the $\mathrm{COOH}^{\bullet}$ radicals via ZPE-corrected energy barriers and reaction energies of about $4-5 \mathrm{kcal} \mathrm{mol}^{-1}$ and $-22 \mathrm{kcal} \mathrm{mol}^{-1}$, respectively. The $\mathrm{COOH}^{\bullet}$ radicals couple with incoming $\mathrm{NH}=\mathrm{CH}_{2}$ molecules (experimentally detected in the ISM) to form the $\mathrm{NHCH}_{2} \mathrm{COOH}^{\bullet}$ radical glycine through energy barriers of $12 \mathrm{kcal} \mathrm{mol}^{-1}$, exceedingly high at ISM cryogenic temperatures. Nonetheless, when $\mathrm{H}_{3} \mathrm{O}^{+}$is present, one proton may be barrierless transferred to $\mathrm{NH}=\mathrm{CH}_{2}$ to give $\mathrm{NH}_{2}=\mathrm{CH}_{2}{ }^{+}$. This latter may react with the $\mathrm{COOH}^{\bullet}$ radical to give the $\mathrm{NH}_{2} \mathrm{CH}_{2} \mathrm{COOH}^{+\bullet}$ glycine radical cation which can then be transformed into the $\mathrm{NH}_{2} \mathrm{CHC}(\mathrm{OH})_{2}{ }^{+\bullet}$ species (the most stable form of glycine in its radical cation state) or into the $\mathrm{NH}_{2} \mathrm{CHCOOH}^{\bullet}$ neutral radical glycine. Estimated rate constants of these events suggest that they are kinetically feasible at temperatures of $100-200 \mathrm{~K}$, which indicate that their occurrence may take place in hot molecular cores or in comets exposed to warmer regions of solar systems. Present results provide quantum chemical evidence that defects formed on water ices due to the harsh-physical conditions of the ISM may trigger reactions of cosmochemical interest. The relevance of surface $\mathrm{H}_{3} \mathrm{O}^{+}$ions to facilitate chemical processes by proton transfer (i.e., acting as acidic catalysts) is highlighted, and plausible ways of their formation at the water-ice surface in the ISM are also discussed.
\end{abstract}

Key words: astrochemistry - cosmic rays - ISM: molecules - molecular processes - ultraviolet: ISM

Online-only material: color figures

\section{INTRODUCTION}

The existence of molecules of biological interest in the interstellar medium (ISM) has attracted great attention, especially due to its direct connection with the chemical evolution of matter and ultimately with the origin of life. Direct spectroscopic observations evidence the presence of a wide variety of interstellar molecules (Ehrenfreund \& Charnley 2000; Herbst \& van Dishoeck 2009; van Dishoeck 1998, 2004), some of them being of prebiotic relevance such as aminoacetonitrile (Belloche et al. 2008), the glycine precursor. Careful analysis of carbonaceous chondrite meteorites fallen on Earth (Cronin \& Pizzarello 1997; Ehrenfreund \& Sephton 2006; Pizzarello 2006; Pizzarello et al. 2008) and, more recently, of dust grains collected in comet 81P/Wild2 by the Stardust spacecraft (Elsila et al. 2009; Glavin et al. 2008; Sandford et al. 2006) reveal the existence of abiotic organic matter and amino acid related species, these latter being of special relevance. In addition, several experiments carried out in Earth laboratories based on VUV irradiation of interstellar ice analogs at ultra-cold temperatures simulated conditions believed to exist on ice-coated interstellar grains, and resulted in the successful synthesis of amino acids and other organic molecules (Bernstein et al. 2002; Muñoz Caro et al. 2002). A possible scenario linking all these facts would be that universe acts as a giant factory (especially dense molecular clouds), synthesizing molecules that could have been entrapped and carried by asteroidal bodies and finally transported and released to the early Earth during the period of heavy bombardment (Chyba \& Sagan 1992; Oró 1961).

Among the amino acids, glycine $\left(\mathrm{NH}_{2} \mathrm{CH}_{2} \mathrm{COOH}\right.$, Gly) is the simplest one and because of that it has been intensively searched for in the ISM. Numerous attempts aimed to its detection have been carried out over the years without giving a firm identification. Notwithstanding, several experiments have shown that Gly can be formed in a laboratory under conditions simulating the ISM ones. For instance, VUV photolysis or cosmic rays irradiation of interstellar ice analogs (i.e., made by $\mathrm{H}_{2} \mathrm{O}, \mathrm{NH}_{3}, \mathrm{CH}_{4}, \mathrm{CH}_{3} \mathrm{OH}, \mathrm{CO}, \mathrm{CO}_{2}, \mathrm{HCN}, \mathrm{CH}_{3} \mathrm{CN}$ molecules) followed by warming and acidic hydrolysis of the obtained residue led to the formation of Gly and other amino acids (Bernstein et al. 2002; Elsila et al. 2007; Hudson et al. 2008; Kobayashi et al. 1995; Muñoz Caro et al. 2002; Nuevo et al. 2008; Takano et al. 2002). Moreover, UV irradiation or electron bombardment of $\mathrm{NH}_{3}$ and $\mathrm{CH}_{3} \mathrm{COOH}$ or $\mathrm{CH}_{3} \mathrm{NH}_{2}$ and $\mathrm{CO}_{2}$ ices brings about the Gly molecule (Holtom et al. 2005; Lafosse et al. 2006; Lee et al. 2009), and thermal processing of $\mathrm{CH}_{3} \mathrm{NH}_{2}$ and $\mathrm{CO}_{2}$ in a water-dominated ice forms yielded the formation of $\left[\mathrm{CH}_{3} \mathrm{NH}_{3}{ }^{+}\right]\left[\mathrm{CH}_{3} \mathrm{NHCOO}^{-}\right]$, which after VUV irradiation evolved into $\left[\mathrm{CH}_{3} \mathrm{NH}_{3}{ }^{+}\right]\left[\mathrm{NH}_{2} \mathrm{CH}_{2} \mathrm{COO}^{-}\right]$, a Gly salt precursor (Bossa et al. 2009). In spite of the experimental evidence, very little is known about the mechanistic steps through which amino acids form and about the specific role played by 
the icy dust particles as catalysts. The oldest and most known postulated mechanism for amino acids formation is the Streckertype synthesis. However, both experimental measurements and theoretical calculations seem to rule out this mechanism in the ISM. Indeed, isotopic labeling experiments performed by Elsila et al. (2007) indicate that Gly formed via photoloysis of an $\mathrm{H}_{2} \mathrm{O}: \mathrm{CH}_{3} \mathrm{OH}: \mathrm{HCN}: \mathrm{NH}_{3}$ ice (the initial reactants for the Strecker synthesis) probably proceeds through radical mechanisms, and quantum chemical calculations performed by us (Rimola et al. 2010) showed that, although the water ice significantly catalyzes the Strecker-involved steps due to the proton mobility at the ice surface, the energy barriers still remain high for the ISM conditions.

Direct experimental measurements to elucidate reaction mechanisms are difficult to perform. In contrast, quantum mechanical methods can be readily adopted to study a variety of possible reaction mechanisms by exploring the potential energy surfaces. In this context, the role of the water-ice particles in neutral astrochemical reactions has been theoretically analyzed (Courmier et al. 2005; Chen \& Woon 2011; Kayi et al. 2011; Koch et al. 2008; Rimola et al. 2010; Woon 2001), whereas more complicated reactions involving ion-molecule and radical-molecule mechanisms have been limited to gas phase (Balucani et al. 1999a, 1999b, 2000; Huang et al. 2000; Knowles et al. 2010; Maeda \& Ohno 2006; Woon 2002). In this work, the formation of Gly in the presence of a radical water ice as well as of an ionized water ice (mimicking the effect of UV and cosmic rays irradiation) has been simulated by quantum chemical methods based on density functional theory. The aim of the present work is to contribute to the understanding of interstellar-gas-grain reactions by providing plausible Gly formation pathways as well as analyzing the specific catalytic role of water ice in this process.

\section{COMPUTATIONAL DETAILS}

All calculations have been performed using GAUSSIAN03 programs (Frisch et al. 2004). Density functional methods have been shown to be cost-effective methods and have been used to study a wide variety of closed-shell systems with great accuracy (Koch \& Holthausen 2001; Sholl \& Steckel 2009; Sousa et al. 2007). However, for open-shell systems, calculations carried out by some of us have demonstrated that functionals with a larger percentage of exact exchange, such as BHLYP, provide better results compared to the highly correlated CCSD(T) method (Georgieva et al. 2005; Poater et al. 2004; Rimola et al. 2006; Sodupe et al. 1999). This is due to the fact that GGA or hybrid functionals with small percentages of exact exchange such as B3LYP overstabilize too delocalized situations, as a result of a bad cancellation of the self-interaction part by the exchange-correlation functional. For the present work, the case of the water dimer in its radical cation form (Sodupe et al. 1999) is particularly illuminating for highlighting the role of exact exchange. With B3LYP, the most stable structure was a hemibonded species (i.e., a 3 electron-2 center bond between the $\mathrm{O}$ atoms), while at the BHLYP level, the $\left[\mathrm{OH} \cdots \mathrm{H}_{3} \mathrm{O}\right]^{+\bullet}$ species becomes the most stable structure, in agreement with highly accurate $\operatorname{CCSD}(\mathrm{T})$ results. In the present work, the same calculations have been carried out for other water cluster radical cations $\left(\left(\mathrm{H}_{2} \mathrm{O}\right)_{n} n=3,4,6\right.$, and 8) showing a very similar behavior of the water dimer radical cation, in which BHLYP compares much better than B3LYP with $\mathrm{CCSD}(\mathrm{T})$ results. Accordingly, the structure of the reactants, products, intermediates, and transition structures analyzed in this work have been fully optimized using the hybrid BHLYP (Becke 1993; Lee et al. 1988) functional with the standard $6-311++G(d, p)$ basis set. The open-shell calculations were based on an unrestricted formalism. All structures have been characterized as minima (reactants, products, and intermediates) and saddle points (transition states) by calculating the analytical harmonic frequencies. In some cases, we have also carried out intrinsic reaction coordinate calculations at the same level of theory to ensure the nature of the minima connected by a given transition state. Thermochemical corrections to the electronic energy values to compute ZPE-corrected and free energy values at the temperatures of $10,50,100$, and $200 \mathrm{~K}$ have been carried out using the standard rigid rotor/harmonic oscillator formulas (McQuarrie 1986). In the paper, the figures show the electronic potential energy surfaces of the studied processes, while the ZPE-corrected and free energy values of all stationary points are shown in Table 1.

\section{RESULTS AND DISCUSSION}

\subsection{The Water-ice Models}

In this work we studied the formation of glycine $\left(\mathrm{NH}_{2} \mathrm{CH}_{2} \mathrm{COOH}\right.$, Gly) on water ice surfaces containing radical and radical cations species, to account for the effect of UV radiation and galactic cosmic rays. The incidence of UV radiation on the ice mantles that cover the dust particles usually leads to the homolytic cleavage of chemical bonds and the generation of radical species. Cosmic rays are high energy particles consisting of about $98 \%$ protons $\left(p, \mathrm{H}^{+}\right)$and $2 \%$ helium nuclei $\left(\alpha\right.$-particles, $\left.\mathrm{He}^{2+}\right)$. The effect of the incidence of cosmic rays on solid $\mathrm{CH}_{4}, \mathrm{C}_{2} \mathrm{H}_{4}$, and $\mathrm{C}_{2} \mathrm{H}_{2}$ ices have been deeply studied by Kaiser \& Roessler (1998). Experiments indicate that each MeV cosmic ray particle transfers its kinetic energy to the ice target through inelastic encounters, and that such linear energy transfer leads to electronic excitations at the ice, which in turn lead to fragmentation and radical formation, but also to ionization of the ices. According to that, for the particular case in which the ice is mostly constituted by water, UV radiation and the impact of cosmic rays bring about the surface reactive radicals via homolytic bond cleavage of water at the surfaces (i.e., $\mathrm{H}_{2} \mathrm{O} \rightarrow$ $\mathrm{OH}+\mathrm{H}$ ), and the ionization of the water ice (i.e., formation of radical cations). Consequently, in this work, the glycine formation has been simulated with the presence of both radical neutral and radical cation water-ice models, hence mimicking plausible scenarios derived from the conditions exposed above.

The radical neutral and radical cation cluster models (hereafter referred as rn and rc, respectively) are shown in Figure 1 and are derived from the most stable neutral cluster constituted by eight water molecules (Ferrari et al. 1993; Maheshwary et al. 2001; Ugalde et al. 2000), which is also shown in Figure 1. The rn cluster arises from the removal of one $\mathrm{H}$ atom from one water molecule of the neutral cluster. This process conserves the initial cubic shape of the cluster as the $\mathrm{OH}$ radical group is localized at the corners of the cube. The removal of one electron in the neutral water cluster, followed by electronic and geometry relaxation, leads to the rc cluster model. After geometry optimization of the rc cluster the $\mathrm{H}$ atom of one water is transferred to another water molecule, resulting in the formation of a distonic system with the radical at the $\mathrm{OH}$ group and the positive charge at the $\mathrm{H}_{3} \mathrm{O}^{+}$species embedded in the cluster; that is, with the radical and the cationic species located far apart in the 
Table 1

Relative ZPE-corrected Electronic Energies $\left(\Delta_{\mathrm{rel}} U_{0}\right)$, and Relative Free Energies Computed at $T=10,50,100$, and $200 \mathrm{~K}\left(\Delta_{\mathrm{rel}} G_{10}, \Delta_{\mathrm{rel}} G_{50}, \Delta_{\mathrm{rel}} G_{100}\right.$, and $\Delta_{\text {rel }} G_{200}$, Respectively) for the Stationary Points Shown in the Energy Profiles of Figures 2-5

\begin{tabular}{|c|c|c|c|c|c|c|}
\hline Profile & Species & $\Delta_{\text {rel }} U_{0}$ & $\Delta_{\mathrm{rel}} G_{10}$ & $\Delta_{\mathrm{rel}} G_{50}$ & $\Delta_{\text {rel }} G_{100}$ & $\Delta_{\text {rel }} G_{200}$ \\
\hline \multirow[t]{3}{*}{ Figure 2(a) } & rn-R1 & 0.0 & 0.0 & 0.0 & 0.0 & 0.0 \\
\hline & rn-TS1 & 4.1 & 4.2 & 4.3 & 4.6 & 5.5 \\
\hline & rn-P1 & -22.8 & -22.8 & -22.6 & -22.1 & -21.0 \\
\hline \multirow[t]{7}{*}{ Figure 2(b) } & rc-R1 & 0.0 & 0.0 & 0.0 & 0.0 & 0.0 \\
\hline & rc-TS1 & 0.5 & 0.5 & 0.5 & 0.6 & 0.8 \\
\hline & rc-I1 & -1.4 & -1.4 & -1.5 & -1.5 & -1.4 \\
\hline & rc-TS2 & $4.1(5.5)$ & $4.1(5.5)$ & $4.1(5.6)$ & $4.3(5.8)$ & $4.8(6.2)$ \\
\hline & rc-I2 & -18.6 & -18.6 & -18.6 & -18.4 & -17.7 \\
\hline & rc-TS3 & $-18.9(-0.3)$ & $-18.8(-0.2)$ & $-18.8(-0.2)$ & $-18.5(-0.1)$ & $-17.5(0.2)$ \\
\hline & rc-P1 & -22.1 & -22.1 & -21.9 & -21.6 & -20.7 \\
\hline \multirow[t]{3}{*}{ Figure 3(a) } & $\mathrm{rn}-\mathrm{R} 2$ & 0.0 & 0.0 & 0.0 & 0.0 & 0.0 \\
\hline & rn-TS2 & 11.9 & 11.9 & 12.1 & 12.5 & 13.6 \\
\hline & rn-P2 & -11.3 & -11.2 & -11.0 & -10.5 & -9.1 \\
\hline \multirow[t]{3}{*}{ Figure 3(b) } & rc-R2 & 0.0 & 0.0 & 0.0 & 0.0 & 0.0 \\
\hline & rc-TS4 & 12.9 & 12.9 & 13.2 & 13.8 & 15.3 \\
\hline & rc-P2 & -14.3 & -14.3 & -14.0 & -13.3 & -11.4 \\
\hline \multirow[t]{5}{*}{ Figure 4(a) } & $\mathrm{rc}-\mathrm{R} 2$ & 0.0 & 0.0 & 0.0 & 0.0 & 0.0 \\
\hline & rc-TS5 & -0.4 & -0.4 & -0.2 & 0.0 & 0.5 \\
\hline & $\mathrm{rc}-\mathrm{I} 3$ & -2.6 & -2.6 & -2.4 & -2.1 & -1.6 \\
\hline & rc-TS6 & $3.6(6.2)$ & $3.6(6.2)$ & $3.8(6.2)$ & $4.4(6.5)$ & $5.7(7.3)$ \\
\hline & rc-P3 & -7.7 & -7.7 & -7.4 & -6.7 & -5.0 \\
\hline \multirow[t]{7}{*}{ Figure 5(a) } & rc-P3 & -7.7 & -7.7 & -7.4 & -6.7 & -5.0 \\
\hline & rc-TS7 & $-2.4(5.3)$ & $-2.4(5.3)$ & $-2.1(5.3)$ & $-1.5(5.2)$ & $0.0(5.0)$ \\
\hline & rc-I4 & -33.5 & -33.5 & -33.2 & -32.6 & -31.0 \\
\hline & rc-TS8 & $-34.6(-1.1)$ & $-34.6(-1.1)$ & $-34.3(-1.0)$ & $-33.6(-1.0)$ & $-31.9(-0.9)$ \\
\hline & rc-P4 & -36.1 & -36.1 & -35.8 & -35.1 & -33.3 \\
\hline & rc-TS9 & $-31.9(4.2)$ & $-31.9(4.2)$ & $-31.7(4.1)$ & $-31.2(3.9)$ & $-29.7(3.6)$ \\
\hline & rc-P5 & -38.4 & -38.4 & -38.3 & -37.9 & -36.8 \\
\hline
\end{tabular}

Notes. Values in parentheses refer to the intrinsic energy barrier between a given transition state and its immediate intermediate. Units in $\mathrm{kcal}^{\mathrm{mol}}{ }^{-1}$.

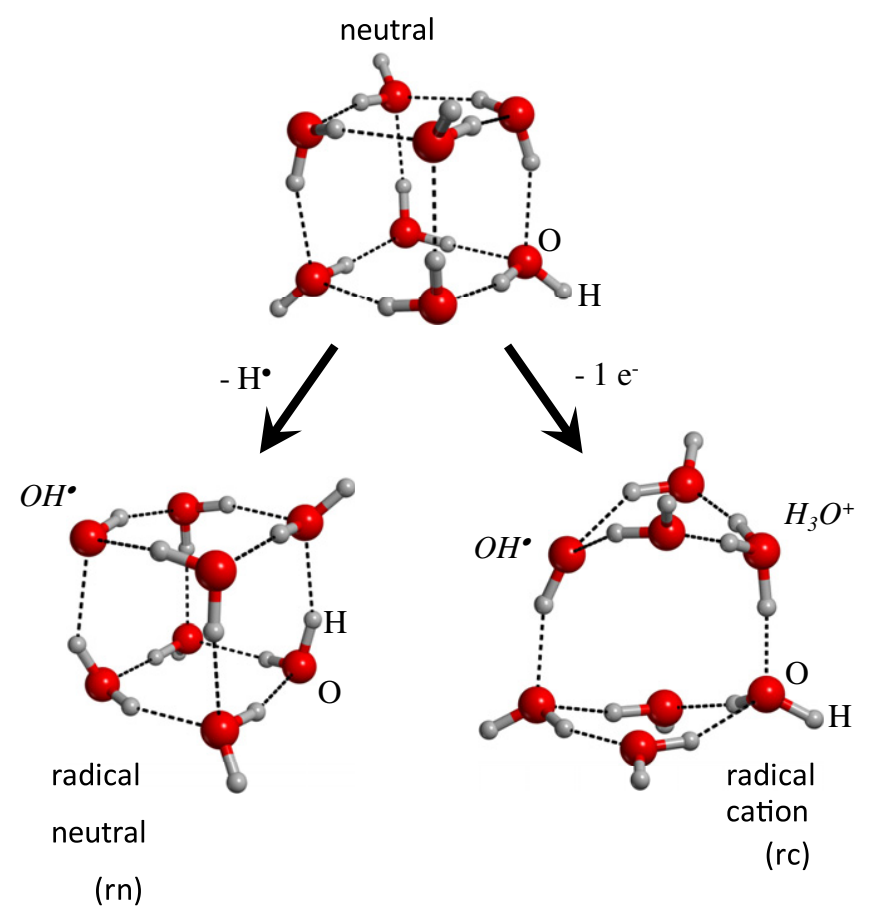

Figure 1. Water-ice cluster models of an ice particle. The neutral cluster is the most stable structure involving eight water molecules. The radical neutral (rn) cluster derives from the neutral one after removing one hydrogen atom $\left(\mathrm{H}^{\bullet}\right)$. The radical cation $(\mathrm{rc})$ cluster derives from the neutral one after removing one electron $\left(e^{-}\right)$

(A color version of this figure is available in the online journal.) cluster. As mentioned in Section 2, such a radical/charge separation has already been observed in the water dimer (Sodupe et al. 1999) and in other clusters.

\subsection{Glycine Formation}

The proposed mechanism for the Gly formation, aimed to be computed in the presence of the $\mathrm{rn}$ and rc water-ice models, is the following one. Because both rn and rc water cluster models enclose $\mathrm{OH}$ surface radical species, the initial step envisages the coupling of this $\mathrm{OH}$ radical with an incoming $\mathrm{CO}$ molecule; i.e., $\mathrm{OH}^{\bullet}+\mathrm{CO} \rightarrow \mathrm{COOH}^{\bullet}$. This reaction has already been postulated as the initial step for the Gly formation by Woon (2002), and it has been studied in gas phase by the same author through highly accurate quantum chemical calculations. However, the study of this reaction in the presence of water-ice dust particles has not been reported yet. Since $\mathrm{NH}=\mathrm{CH}_{2}$ has indeed been detected in the ISM (Dickens et al. 1997), likely as a result of gas-phase $\mathrm{H}$ addition to $\mathrm{HCN}$ (Woon 2002), the second step involves the reaction between the formed $\mathrm{COOH}^{\bullet}$ radical with an incoming methylenimine $\left(\mathrm{NH}=\mathrm{CH}_{2}\right)$ molecule; namely, $\mathrm{COOH}^{\bullet}+\mathrm{NH}=\mathrm{CH}_{2} \rightarrow \mathrm{NHCH}_{2} \mathrm{COOH}^{\bullet}$, which yields a radical glycine-derivative species. Finally, the addition of one $\mathrm{H}$ atom to $\mathrm{NHCH}_{2} \mathrm{COOH}^{\bullet}$ gives the Gly product.

The potential energy profiles for the reaction of the surface radical hydroxyl $\left(\mathrm{OH}^{\bullet}\right.$ surf $)$ groups of the $\mathrm{rn}$ and $\mathrm{rc}$ water-ice models with a CO molecule are shown in Figures 2(a) and (b), respectively, while the relative ZPE-corrected and free energy values of the stationary points involved in these profiles with 
(a)
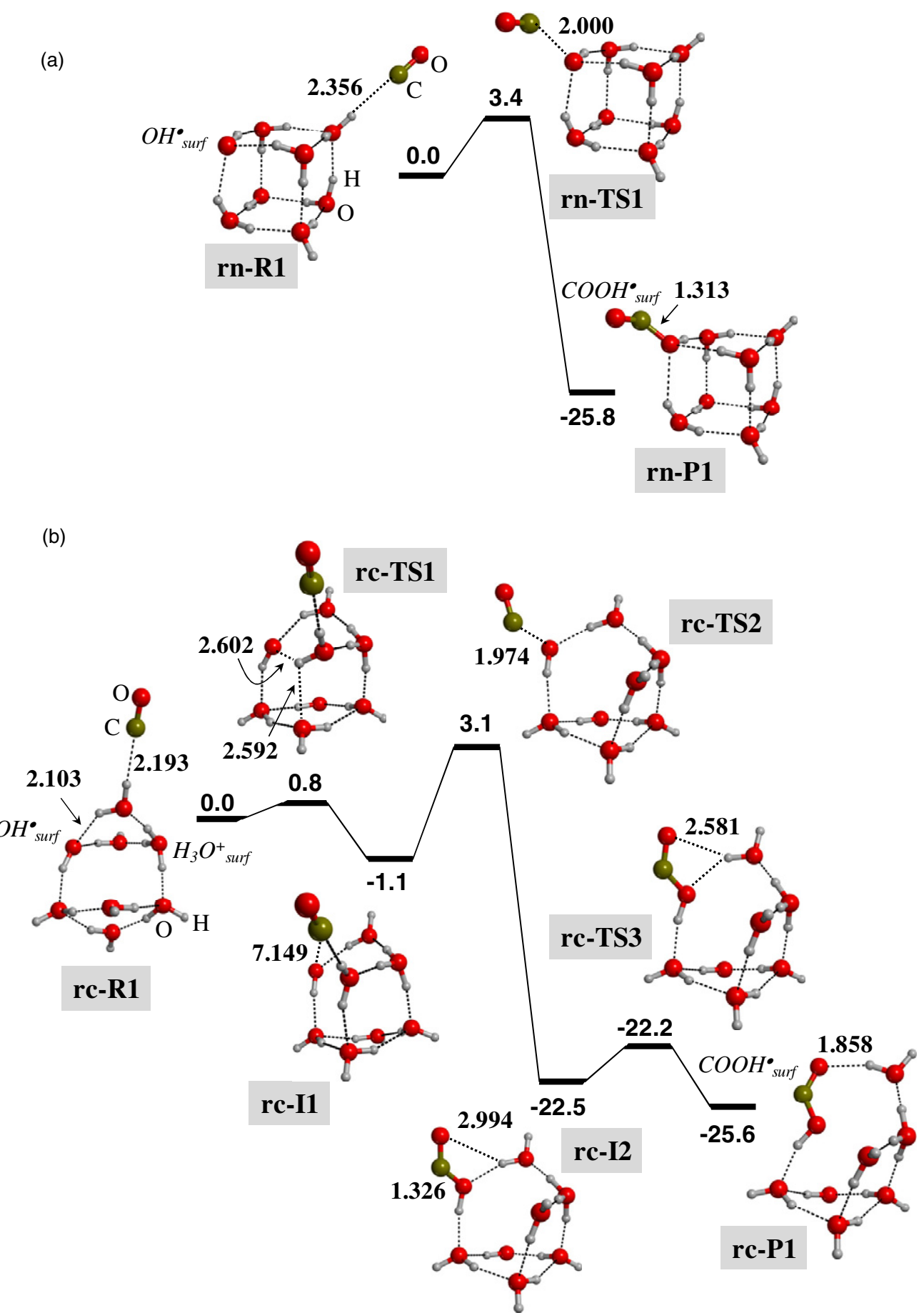

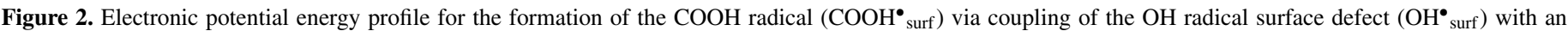
incoming $\mathrm{CO}$ molecule on (a) the rn water-ice cluster and (b) the rc water-ice cluster. The zero energy reference states for profiles (a) and (b) refer to the rn-R1 and rc-R1 structures, respectively. Units in $\mathrm{kcal} \mathrm{mol}^{-1}$. Distances in $\AA$.

(A color version of this figure is available in the online journal.)

respect to the reference state are shown in Table 1. In both cases, the pre-reactant structures have the $\mathrm{CO}$ molecule H-bonded to a water molecule of the ice cluster (rn-R1 and rc-R1). In the rn cluster, due to the high symmetry of the cluster, $\mathrm{CO}$ can equivalently interact with one of the three free $\mathrm{OH}$ groups of the cornering waters, as it is the case for the rn-R1 adduct. In contrast, the free $\mathrm{OH}$ groups in the rc cluster are not all equivalent and, accordingly, different possibilities have been explored. Results, although showing that all the available waters have similar propensity to receive $\mathrm{CO}$, indicate that the $\mathrm{OH}$ group of the water molecule closest to the $\mathrm{OH}^{\bullet}$ surf group is the most favorable one (rc-R1).

For the rn case, a direct coupling between the $\mathrm{C}$ atom of $\mathrm{CO}$ and the $\mathrm{O}$ atom of $\mathrm{OH}^{\circ}$ surf proceeds through a ZPEcorrected energy barrier $\left(\Delta U_{0}{ }^{\neq}\right)$of $4.1 \mathrm{kcal} \mathrm{mol}^{-1}$ (rn-TS1). Such a coupling leads to the formation of the carboxyl radical $\left(\mathrm{COOH}^{\bullet}\right.$ surf $)$ with a very favorable ZPE-corrected reaction energy $\left(\Delta_{\mathrm{rx}} U_{0}\right)$ of $-22.8 \mathrm{kcal} \mathrm{mol}^{-1}$ (rn-P1). The formed $\mathrm{COOH}^{\circ}$ surf remains attached to the water surface through its $\mathrm{OH}$ group in a similar way as the $\mathrm{OH}^{\bullet}$ surf in the pristine rn cluster. 
Table 2

Calculated Rate Constants Using the Classical Eyring Equation at $T=10,50,100$, and $200 \mathrm{~K}\left(k_{10}, k_{50}, k_{100}\right.$, and $k_{200}$, Respectively) for the Steps Involved in the Energy Profiles Shown in Figures 2-5

\begin{tabular}{|c|c|c|c|c|c|}
\hline Profile & Step & $k_{10}$ & $k_{50}$ & $k_{100}$ & $k_{200}$ \\
\hline Figure 2(a) & $\mathrm{rn}-\mathrm{R} 1 \rightarrow \mathrm{rn}-\mathrm{TS} 1$ & $3.82 \times 10^{-80}$ & $1.28 \times 10^{-7}$ & 143.23 & $4.32 \times 10^{6}$ \\
\hline Figure 2(b) & $\begin{aligned} \mathrm{rc}-\mathrm{R} 1 & \rightarrow \mathrm{rc}-\mathrm{TS} 1 \\
\mathrm{rc}-\mathrm{I} 1 & \rightarrow \mathrm{rc}-\mathrm{TS} 2 \\
\mathrm{rc}-\mathrm{I} 2 & \rightarrow \mathrm{rc}-\mathrm{TS} 3\end{aligned}$ & $\begin{array}{c}3.35 \\
8.26 \times 10^{-110} \\
\ldots{ }^{a}\end{array}$ & $\begin{array}{c}6.37 \times 10^{9} \\
3.91 \times 10^{-13} \\
\ldots{ }^{a}\end{array}$ & $\begin{array}{c}1.23 \times 10^{11} \\
5.39 \times 10^{-1} \\
\ldots\end{array}$ & $\begin{array}{l}6.04 \times 10^{11} \\
6.81 \times 10^{5} \\
2.65 \times 10^{12}\end{array}$ \\
\hline Figure 3(a) & $\mathrm{rn}-\mathrm{R} 2 \rightarrow \mathrm{rn}-\mathrm{TS} 2$ & $1.46 \times 10^{-250}$ & $9.61 \times 10^{-42}$ & $8.85 \times 10^{-16}$ & $6.01 \times 10^{-3}$ \\
\hline Figure 3(b) & $\mathrm{rc}-\mathrm{R} 2 \rightarrow \mathrm{rc}-\mathrm{TS} 4$ & $5.68 \times 10^{-272}$ & $2.05 \times 10^{-46}$ & $1.52 \times 10^{-18}$ & $8.02 \times 10^{-5}$ \\
\hline Figure 4(a) & $\begin{array}{r}\mathrm{rc}-\mathrm{R} 2 \rightarrow \mathrm{rc}-\mathrm{TS} 5 \\
\mathrm{rc}-\mathrm{I} 3 \rightarrow \mathrm{rc}-\mathrm{TS} 6\end{array}$ & 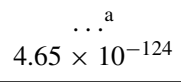 & $\begin{array}{c}\cdots^{\mathrm{a}} \\
4.45 \times 10^{-16}\end{array}$ & $\begin{array}{c}\ldots{ }^{\mathrm{a}} \\
1.13 \times 10^{-2}\end{array}$ & $\begin{array}{l}1.24 \times 10^{12} \\
4.67 \times 10^{4}\end{array}$ \\
\hline Figure 5(a) & $\begin{array}{r}\text { rc-P3 } \rightarrow \text { rc-TS7 } \\
\text { rc-I4 } \rightarrow \text { rc-TS8 } \\
\text { rc-P4 } \rightarrow \text { rc-TS9 }\end{array}$ & $\begin{array}{c}2.60 \times 10^{-106} \\
\ldots{ }^{\mathrm{a}} \\
\cdots \\
1.35 \times 10^{-80}\end{array}$ & $\begin{array}{c}7.41 \times 10^{-12} \\
\ldots{ }^{\mathrm{a}} \\
1.31 \times 10^{-6}\end{array}$ & $\begin{array}{c}8.67 \\
\ldots a \\
5.57 \times 10^{3}\end{array}$ & $\begin{array}{c}1.40 \times 10^{7} \\
\ldots{ }^{\mathrm{a}} \\
5.80 \times 10^{8}\end{array}$ \\
\hline
\end{tabular}

Notes. Units in $\mathrm{s}^{-1}$.

a These values cannot be computed since, after applying the thermal and entropic corrections, the Gibbs energies of the transition state become lower than the immediate precursor, and accordingly the energy barriers are negative.

For the rc case, an internal rearrangement of the cluster toward the rc-I1 cluster is first needed for the $\mathrm{OH}^{\bullet}{ }_{\text {surf }}-\mathrm{OC}$ coupling to take place through the rc-TS2 species. This rearrangement involves the breaking of one $\mathrm{H}$-bond of the $\mathrm{OH}^{\bullet}$ surf with the adjacent water $\left(\Delta U_{0} \neq=0.5 \mathrm{kcal} \mathrm{mol}^{-1}\right.$, see rc-TS1), hence enhancing the propensity of the $\mathrm{OH}^{\bullet}$ surf to react with the CO molecule. The second step of the profile envisages the formation of the $\mathrm{COOH}^{\bullet}$ surf molecule, which, similar to the rn case, occurs with an intrinsic low $\Delta U_{0} \neq$ and a very favorable $\Delta_{\mathrm{rx}} U_{0}(5.5$ and $-18.6 \mathrm{kcal} \mathrm{mol}^{-1}$, rc-TS2 and rc-I2, respectively). As a final step, rc-I2 undergoes an H-bonding rearrangement in such a way that the final structure (rc-P1, more stable than rc-I2 by about $3.5 \mathrm{kcal} \mathrm{mol}^{-1}$ ) exhibits the $\mathrm{COOH}^{\bullet}$ surf radical in a more favorable $\mathrm{H}$-bonding interaction with the ice particle. This transformation, which, when accounting for ZPE-corrections, takes place in a barrierless fashion (i.e., negative $\Delta U_{0} \neq$ value, see Table 1), envisages a $\mathrm{COOH}^{\bullet}$ surf group hoping or oscillating over the cluster in order to reach the most stable state. Interestingly, the deformation cost of the water clusters during these processes is only $0.1 \mathrm{kcal} \mathrm{mol}^{-1}$, so that cluster deformations do not alter significantly the computed energy barriers. Both rn and rc processes have similar $\Delta U_{0} \neq$ and $\Delta_{\mathrm{rx}} U_{0}$ values irrespective of the kind of defects present on the water-ice clusters. This is reasonable since in both cases only the $\mathrm{OH}^{\bullet}$ surf groups are involved, the $\mathrm{H}_{3} \mathrm{O}^{+}$surf present in the rc cluster not playing any active role in the reaction. Noticeably, the reaction profile computed in the gas phase (i.e., $\mathrm{OH}^{\bullet}+\mathrm{CO} \rightarrow \mathrm{COOH}^{\bullet}$ ) also has similar energetic values $\left(\Delta U_{0} \neq=4.1 \mathrm{kcal} \mathrm{mol}^{-1}\right.$ and $\Delta_{\mathrm{rx}} U_{0}=$ $-19.0 \mathrm{kcal} \mathrm{mol}^{-1}$ ). This indicates that the icy particles do not exert any specific catalytic effect as they only trap the active $\mathrm{OH}^{\bullet}$ surf species within the particle. The rate constants for each step shown in the energy profiles of Figure 2 have been computed using the corresponding free energy barriers calculated at the considered temperatures (Table 1) by means of the Eyring's equation (values shown in Table 2). In chemical kinetics, the classical Eyring's equation adopts the following form for unimolecular reactions:

$$
k=\frac{k_{B} T}{h} \exp \left(-\frac{\Delta G^{\neq}}{R T}\right)
$$

where $k_{\mathrm{B}}$ is the Boltzmann constant, $T$ is the absolute temperature, $h$ is the Planck's constant, $\Delta G^{\neq}$is the intrinsic free energy barrier computed at a temperature $T$, and $R$ is the gas constant. It allows us to estimate reaction rates from a given free energy barrier and relates the reaction rates to temperature. In this work, we consider the reactions as unimolecular because, although the reactions involve two molecules, they belong to the same pre-reactant complexes and this is maintained along the process. Reaction rate estimations result that at very low temperatures (i.e., 10 and $50 \mathrm{~K}$ ) the computed $k$ values are exceedingly small and, accordingly, the reactions are kinetically hampered. In contrast, between 100 and $200 \mathrm{~K}$, the calculated rate constants indicate that reactions are indeed feasible on astronomical time scales.

The next step toward the formation of Gly envisages the reaction of $\mathrm{NH}=\mathrm{CH}_{2}$ with the carboxyl radical. Figure 3 reports the electronic potential energy profiles for this reaction on the (a) rn and (b) rc ice cluster models. Table 1 shows the calculated relative ZPE-corrected and free energies of each stationary point. It is worth mentioning that these two energy profiles have different zero energy reference states with respect to those of the profiles of Figure 2 because $\mathrm{NH}=\mathrm{CH}_{2}$ is now present as a new reactant. Similar to the previous step, the pre-reactant complexes envisage $\mathrm{NH}=\mathrm{CH}_{2} \mathrm{H}$-bonded to a water molecule of the ice clusters (rn-R2 and rc-R2, respectively). Similar to the case of $\mathrm{CO}$ interacting with the rn cluster, we chose one of the symmetry equivalent positions to adsorb $\mathrm{NH}=\mathrm{CH}_{2}$ (see rn-R2). For the rc cluster, the rc-R2 structure was the most stable one over all other positions. From both rn-R2 and rc-R2 structures, the $\mathrm{NHCH}_{2} \mathrm{COOH}^{\bullet}\left(\mathrm{Gly}^{\bullet}-1\right)$ radical molecule is formed with large and negative $\Delta_{\mathrm{rx}} U_{0}$ values $\left(-11.3\right.$ and $-14.3 \mathrm{kcal} \mathrm{mol}^{-1}$ on rn and $\mathrm{rc}$, respectively). Unfortunately, the ZPE-corrected energy barriers are very high (11.9 and $12.9 \mathrm{kcal} \mathrm{mol}^{-1}$, for rc-TS2 and rc-TS4) under interstellar conditions. This is indeed confirmed by the calculated rate constants (see Table 2), in which, for all the considered temperatures, they resulted exceedingly small to provide any significant reaction progress. Remarkably, the energy barriers are similar on the rn and rc clusters because, for both systems, the reactions only involve the $\mathrm{NH}=\mathrm{CH}_{2}$ and $\mathrm{COOH}^{\bullet}$ surf, the $\mathrm{H}_{3} \mathrm{O}^{+}$surf of the rc system acting again as a 

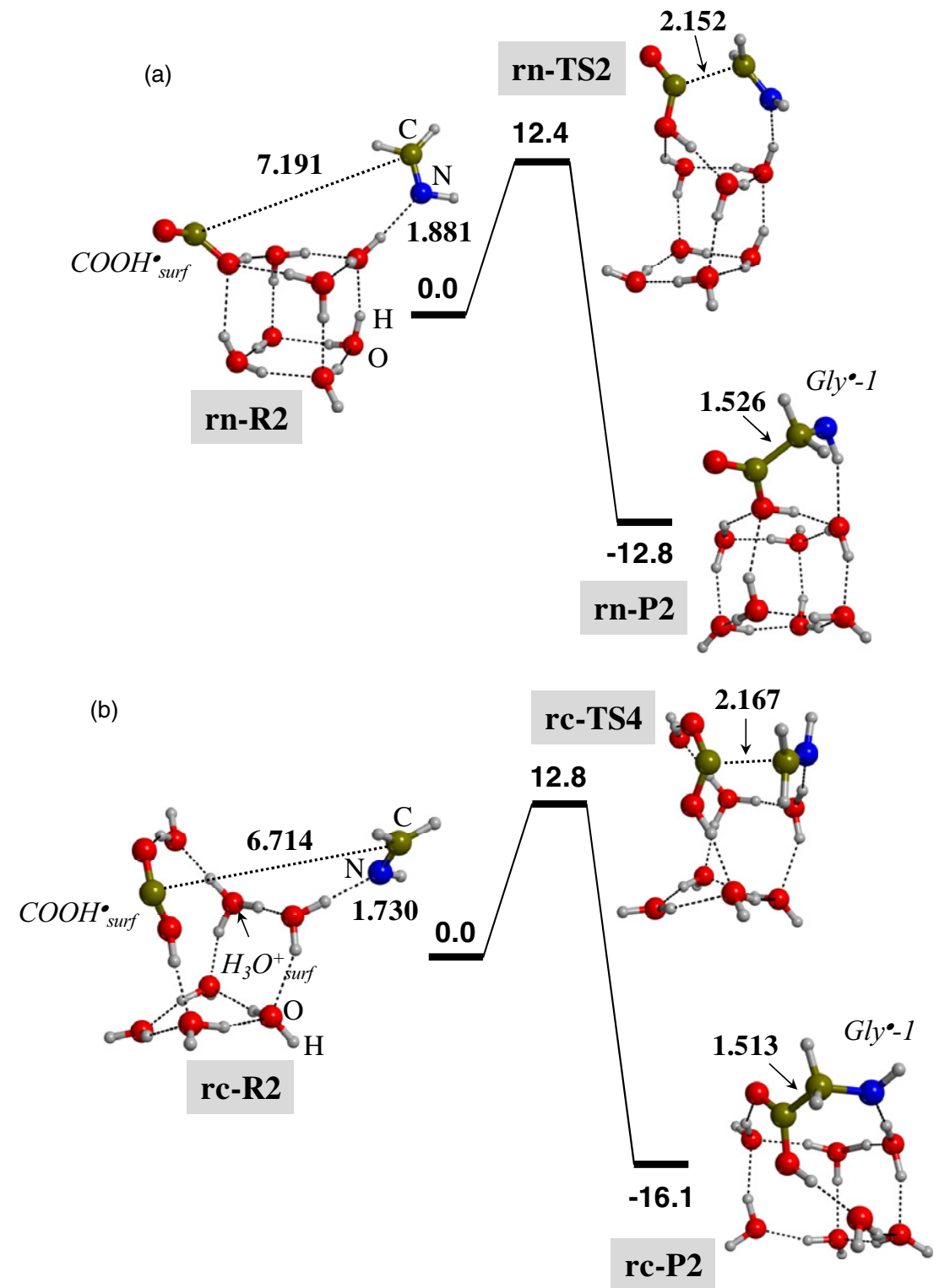

Figure 3. Electronic potential energy profile for the formation of the $\mathrm{NHCH}_{2} \mathrm{COOH}$ radical glycine derivative $\left(\mathrm{Gly}^{\bullet}-1\right)$ via coupling of the $\mathrm{COOH}$ radical $\left(\mathrm{COOH}{ }^{\bullet}\right.$ surf $)$ and an incoming $\mathrm{NH}=\mathrm{CH}_{2}$ molecule: (a) on the rn water-ice cluster and (b) on the rc water-ice cluster. The zero energy reference states for profiles (a) and (b) refer to the rn-R1 and rc-R1 structures, respectively. Units in $\mathrm{kcal} \mathrm{mol}^{-1}$. Distances in $\AA$.

(A color version of this figure is available in the online journal.)

mere spectator species. The same reaction computed in the gas phase gives similar $\Delta_{\mathrm{rx}} U_{0}$ but definitely higher $\Delta U_{0} \neq$ values (-15.7 and $18.5 \mathrm{kcal} \mathrm{mol}^{-1}$, respectively). This difference is due to the extra energetic cost of breaking the strong H-bond between the $\mathrm{COOH}^{\bullet}$ and $\mathrm{NH}=\mathrm{CH}_{2}$ in the pre-reactants, which is missing when the reaction occurs at the ice cluster. Thus, for this particular case, the role of the surface water molecules is to "prepare" the reactants for the subsequent step.

An alternative mechanism for Gly formation on the rc ice cluster model is possible, as shown in the potential energy profile of Figure 4(a) and the relative ZPE-corrected and free energies of Table 1. In this mechanism, the pre-reactant complex is still the rc-R2 structure, which is also taken as the zero energy reference state. At variance with steps of Figure 3, a proton transfer from the $\mathrm{H}_{3} \mathrm{O}^{+}$surf to the $\mathrm{NH}=\mathrm{CH}_{2}$ takes place before the formation of the $\mathrm{C}-\mathrm{C}$ bond. The resulting transition state (rc-TS5) shows that the proton transfer process is assisted by the water molecule that $\mathrm{H}$-bonds the $\mathrm{NH}=\mathrm{CH}_{2}$ in $\mathbf{r c}-\mathbf{R 2}$, resulting in a potential energy barrier of $0.9 \mathrm{kcal} \mathrm{mol}^{-1}$, which in turn becomes virtually zero when including ZPE-corrections. The resultant $\mathbf{r c}-\mathbf{I 3}$ intermediate exhibits the newly formed methylenimmonium $\left(\mathrm{NH}_{2}=\mathrm{CH}_{2}{ }^{+}\right)$ion. The rc-I3 intermediate evolves toward the final species rc-P3 by the coupling between the $\mathrm{NH}_{2}=\mathrm{CH}_{2}{ }^{+}$and $\mathrm{COOH}^{\circ}$ surf molecules via the rc-TS6 transition state with an intrinsic $\Delta U_{0} \neq$ of $6.2 \mathrm{kcal} \mathrm{mol}^{-1}$. Here, the cluster deformation cost has been computed to be $2.4 \mathrm{kcal} \mathrm{mol}^{-1}$, indicating a possible overestimation of the computed energy barriers. The calculated rate constants for this step indicate that, while at $T=10$ and $50 \mathrm{~K}$ the process is kinetically hampered, at $T=100$ and $200 \mathrm{~K}$ the process may indeed occur (see Table 2). The resulting species (see rc-P3) is glycine in one of its radical cation forms $\left(\mathrm{NH}_{2} \mathrm{CH}_{2} \mathrm{COOH}^{+\bullet}\right.$, Gly $\left.^{+\bullet}-1\right)$ stabilized by $\Delta_{\mathrm{rx}} U_{0}$ of $-7.7 \mathrm{kcal} \mathrm{mol}^{-1}$. It is worth mentioning that the mechanism of Figure 4(a) highlights the 


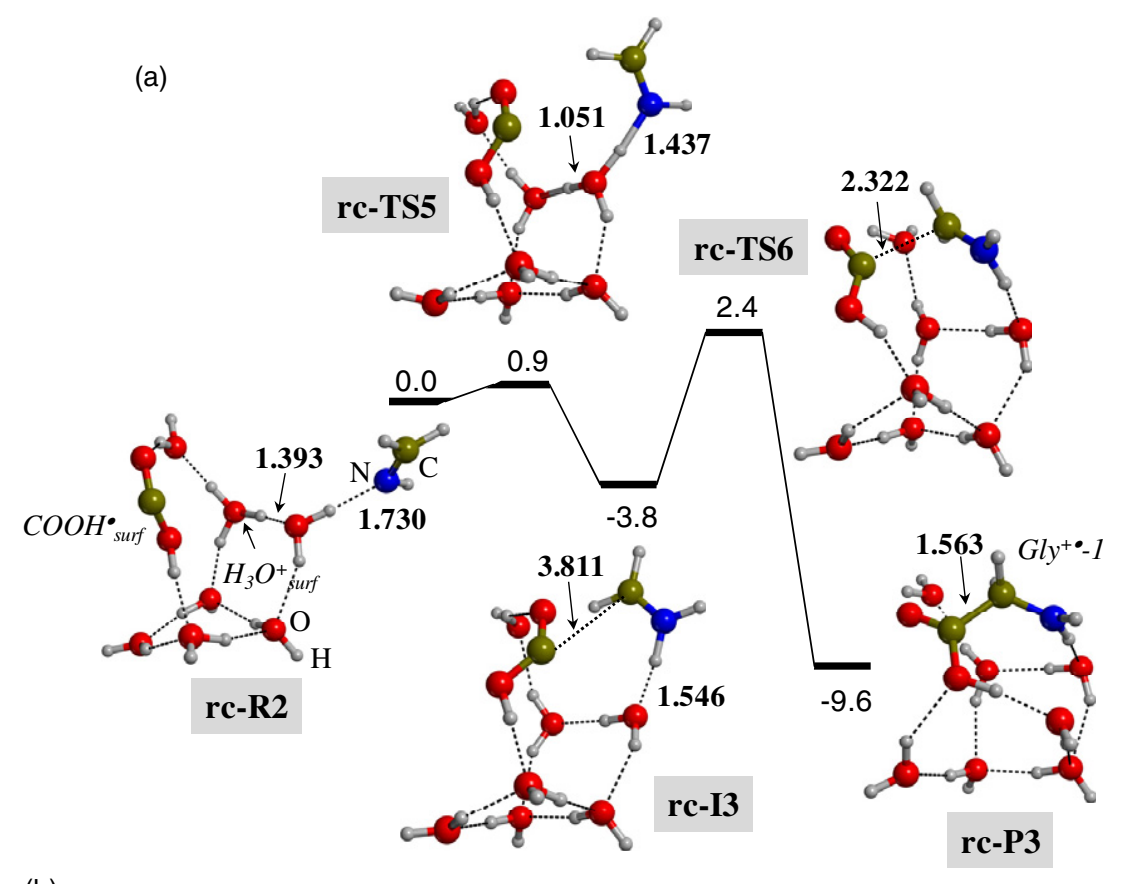

(b)

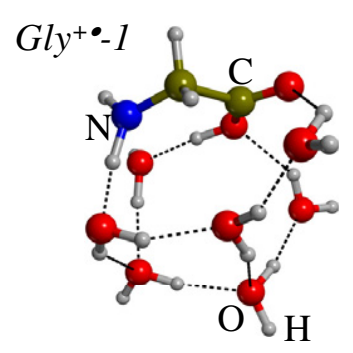

rc-P3

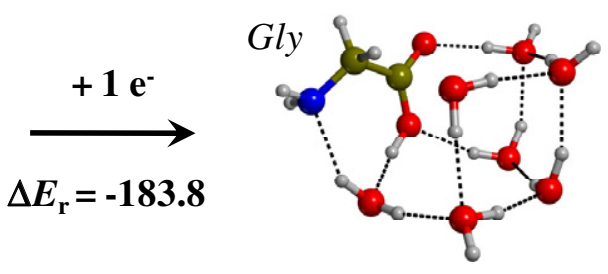

n-P1

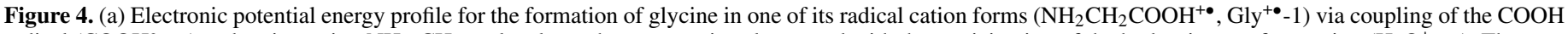

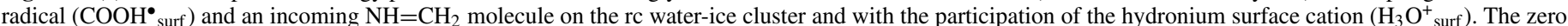

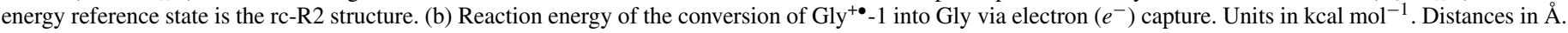
(A color version of this figure is available in the online journal.)

key role of the $\mathrm{H}_{3} \mathrm{O}^{+}$surf for the $\mathrm{NH}_{2}=\mathrm{CH}_{2}{ }^{+}$ion formation through a proton transfer mechanism. This, in turn, enables the radical-ion coupling between the $\mathrm{COOH}^{\bullet}$ surf and $\mathrm{NH}_{2}=\mathrm{CH}_{2}{ }^{+}$ moieties, with a sizeable lowering of the $\Delta U_{0} \neq$ barrier compared with the $\mathrm{COOH}^{\bullet}$ surf and $\mathrm{NH}=\mathrm{CH}_{2}$ coupling. We suggest that a favorable electrostatic interaction between $\mathrm{NH}_{2}=\mathrm{CH}_{2}{ }^{+}$and $\mathrm{COOH}^{\bullet}$ surf species is the key element of the barrier lowering. The very low energy barrier of the initial proton transfer (rcTS5) is consistent with the experimental measurements related to cosmic rays bombardment onto ices. Pilling et al. (2010) observed the presence of $\mathrm{NH}_{4}{ }^{+}$during the interaction of highly charged and energetic ions with $\mathrm{H}_{2} \mathrm{O}: \mathrm{NH}_{3}$ ices, which was explained by proton exchange between neutral and ionized species. These experimental data suggest that the ionized ices are indeed unstable and accordingly, very reactive. In the present case, the reactivity of the charged ice particles is shown by the ease proton transfer and the stability of the formed intermediate (rc-I3 is $-2.6 \mathrm{kcal} \mathrm{mol}^{-1}$ below to rc-R2). As a final step, a possible reaction channel to transform $\mathrm{Gly}^{+\bullet}-1$ species into Gly refers to the capture of an external electron by rc-P3, converting the radical cation system in a neutral one. The extra electron may arise from either the flow of low-energy interstellar particles or via electron transfer from any anionic species present in the ISM such as $\mathrm{OCN}^{-}$. When one electron is added to rc-P3 it evolves to its neutral-analog system, the process being exoenergetic by $-183.8 \mathrm{kcal} \mathrm{mol}^{-1}$ (Figure 4(b)).

Literature data show that the most stable gas-phase glycine radical cation is a diol structure $\mathrm{NH}_{2} \mathrm{CHC}(\mathrm{OH})_{2}{ }^{+\bullet}\left(\mathrm{Gly}^{+\bullet}-2\right)$ and not $\mathrm{NH}_{2} \mathrm{CH}_{2} \mathrm{COOH}^{+\bullet}\left(\mathrm{Gly}^{+\bullet}-1\right)$. This is due to the stronger stabilizing captodative effects in $\mathrm{Gly}^{+\bullet}-2$ compared to $\mathrm{Gly}^{+\bullet}-1$ (Bordwell \& Lynch 1989; Simon et al. 2002; Yu et al. 1995). Accordingly, the transformation of $\mathrm{Gly}^{+\bullet}-1$ into $\mathrm{Gly}^{+\bullet}-2$ on the water-ice cluster has also been considered as presented in Figure 5(a). This process starts from rc-P3 but, as it can be considered as the next step of the mechanism shown in Figure 4(a), the zero energy reference state is rc-R2 (the reference state of Figure 4(a)). The reaction proceeds in a first step through the proton transfer from the $\mathrm{CH}_{2}$ of rc-P3 to an adjacent water molecule (rc-TS7, $\Delta U_{0} \neq=5.3 \mathrm{kcal} \mathrm{mol}^{-1}$ ), evolving through the intermediate rc-I4 $\left(\Delta U_{0}=-28.4 \mathrm{kcal} \mathrm{mol}^{-1}\right)$, in which the $\mathrm{H}_{3} \mathrm{O}^{+}$species is at the ice surface. In the subsequent step, the $\mathrm{NH}_{2} \mathrm{CHC}(\mathrm{OH})_{2}{ }^{+\bullet}\left(\mathrm{Gly}^{+\bullet}-2\right)$ species is formed (rc-P4) through the rc-TS8 transition state in which the $\mathrm{C}-\mathrm{OH}$ group is formed via the proton relay mechanism initiated by the $\mathrm{H}_{3} \mathrm{O}^{+}$. Interestingly, the direct proton transfer from the $\mathrm{CH}_{2}$ to the $\mathrm{C}=\mathrm{O}$ groups to give $\mathrm{Gly}^{+\bullet}-2$ resulted in an intrinsic barrier of $\Delta U_{0} \neq=$ $32.4 \mathrm{kcal} \mathrm{mol}^{-1}$, too high to be feasible in the ISM. Gly ${ }^{+}-2$ can evolve through the most stable isomer of the glycine radical 


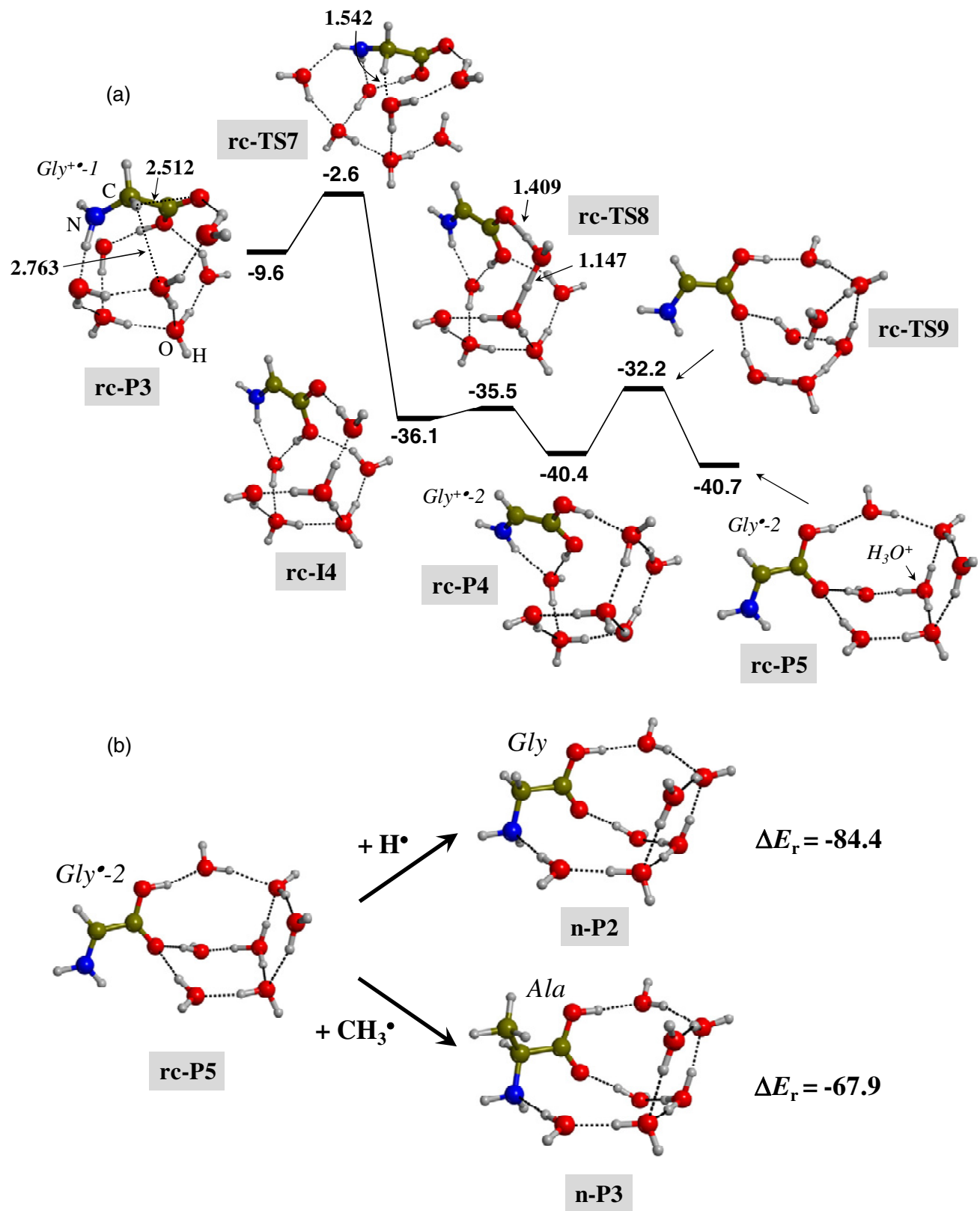

Figure 5. (a) Electronic potential energy profile for the conversion of $\mathrm{Gly}^{+\bullet}-1$ to the most stable forms of glycine in its radical cation $\left(\mathrm{NH}_{2} \mathrm{CHC}(\mathrm{OH})_{2}^{+\bullet}, \mathrm{Gly}^{+\bullet}-2\right)$ and radical neutral $\left(\mathrm{NH}_{2} \mathrm{CHCOOH}^{\bullet}\right.$, Gly $\left.{ }^{\bullet}-2\right)$ states. The zero energy reference state is the rc-R2 structure shown in Figure 4(a). (b) Reaction energies of the addition of hydrogen atom $\left(\mathrm{H}^{\bullet}\right)$ and methyl radical $\left(\mathrm{CH}_{3}{ }^{\bullet}\right)$ to $\mathrm{Gly}^{\bullet}-2$ to give glycine (Gly) and alanine (Ala), respectively. Units in kcal mol ${ }^{-1}$. Distances in $\AA$.

(A color version of this figure is available in the online journal.)

$\mathrm{NH}_{2} \mathrm{CHCOOH}^{\bullet}\left(\mathrm{Gly}^{\bullet}-2\right)$ (Yu et al. 1995), following the path shown in the last step of Figure 5(a). From rc-P4, a proton transfer from an $\mathrm{OH}$ group of $\mathrm{Gly}^{+\bullet}-2$ to the ice takes place via an intrinsic $\Delta U_{0} \neq$ of $4.2 \mathrm{kcal} \mathrm{mol}^{-1}$ (rc-TS9), in such a way that $\mathrm{Gly}^{\bullet}-2$ is formed by restoring the $\mathrm{H}_{3} \mathrm{O}^{+}$cation on the icy particle (see rc-P5). The profile of Figure 5(a) has two transition states of similar height (rc-TS7 and rc-TS9) and the reaction rates calculated for these two steps indicate that temperatures in the 100-200 K range are needed to render these steps feasible. As can be seen from Figure 5(a) and data in Table 1, rc-P5 is $2.3 \mathrm{kcal} \mathrm{mol}^{-1}$ lower in energy than rc-P4, suggesting an accumulation of the former species in the ISM. This finding is particularly relevant because Gly ${ }^{\bullet}-2$ can be transformed to Gly in a barrierless and exergonic process by addition of atomic $\mathrm{H}$, particularly abundant in the ISM (see Figure 5(b)). Moreover, by the same mechanism, reactions with other radical species (also present in the ISM) give rise to more complex amino acids, like alanine, through addition of the $\mathrm{CH}_{3}{ }^{\bullet}$ radical (see Figure 5(b)). This suggests a possible mechanism to explain the richness of amino acids (both proteinogenic and not) detected in meteorites fallen on Earth (Pizzarello 2006).

\section{CONCLUDING REMARKS}

BHLYP density functional calculations have been adopted as the accurate method of choice to simulate the formation of glycine on water-ice cluster models envisaging $\mathrm{OH}$ radical and $\mathrm{H}_{3} \mathrm{O}^{+}$species to account for plausible effects of the incidence of UV radiation and cosmic-ray particles on the ice particle. 
The water-ice particle has been modeled using the most stable configuration of eight $\mathrm{H}_{2} \mathrm{O}$ molecules mutually $\mathrm{H}$-bonded which was properly modified by removing either one $\mathrm{H}$ atom or one electron to define either a radical neutral ( $\mathrm{rn}$ ) or a radical cation (rc) ice particle models, respectively.

In both cluster models, the $\mathrm{OH}$ radical at the surface reacts with an incoming $\mathrm{CO}$ molecule with ZPE-corrected energy barriers and reaction energies of about 4 and $-22 \mathrm{kcal} \mathrm{mol}^{-1}$, respectively, to form a $\mathrm{COOH}^{\bullet}$ radical attached at the water ices. The reaction proceeds by the interaction of the $\mathrm{COOH}^{\bullet}$ radical with an incoming $\mathrm{NH}=\mathrm{CH}_{2}$ (usually present in the ISM) to form the $\mathrm{NHCH}_{2} \mathrm{COOH}^{\bullet}$ radical glycine derivative. This step is exergonic but with exceedingly high energy barriers (about 12-13 $\mathrm{kcal} \mathrm{mol}^{-1}$ ) to occur in the ISM. Alternatively, a more favorable path for the formation of a glycine-related species has been computed only for the cluster that encloses, in addition to the $\mathrm{OH}$ radical, the positively charged $\mathrm{H}_{3} \mathrm{O}^{+}$ion. This mechanism starts with a barrierless proton transfer from the $\mathrm{H}_{3} \mathrm{O}^{+}$surface ion toward the incoming $\mathrm{NH}=\mathrm{CH}_{2}$ molecule forming the $\mathrm{NH}_{2}=\mathrm{CH}_{2}{ }^{+}$cation, which in turn couples with the $\mathrm{COOH}^{\bullet}$ radical to yield glycine in one of its radical cation forms $\left(\mathrm{NH}_{2} \mathrm{CH}_{2} \mathrm{COOH}^{+\bullet}\right)$. The global process shows a ZPEcorrected energy barrier and reaction energy of $6 \mathrm{kcal} \mathrm{mol}^{-1}$ and $-8 \mathrm{kcal} \mathrm{mol}^{-1}$, respectively. Furthermore, $\mathrm{NH}_{2} \mathrm{CH}_{2} \mathrm{COOH}^{+\bullet}$ may evolve toward the most stable forms of glycine in its radical cation $\left(\mathrm{NH}_{2} \mathrm{CHC}(\mathrm{OH})_{2}{ }^{+\bullet}\right)$ and radical neutral $\left(\mathrm{NH}_{2} \mathrm{CHCOOH}{ }^{\bullet}\right)$ states. This, in turn, opens up reaction channels by which not only Gly but also more complex amino acids can be formed in ISM via radical-radical coupling reactions.

The free energy barriers of the steps described above have also been computed at temperatures of 10, 50, 100, and $200 \mathrm{~K}$ from which the rate constants have been computed by the classical Eyring formula. Results clearly indicate that in the 10-50 K temperature range these processes are kinetically hampered at the ISM conditions. In contrast, estimated rate constants calculated in the 100-200 K range suggest that the formation of $\mathrm{COOH}^{\bullet}$ (both on the rn and rc water clusters) and of glycinederivative species on the rc cluster are evolving with a reasonable speed. The requested temperatures are higher than those found in dark molecular clouds and are characteristic of hot molecular cores, of comets that have passed through warmer regions of solar systems or of interstellar ices that have experienced thermal shocks.

The present results propose a possible path that leads to the formation of glycine-derivative species which may rationalize the detection of glycine in some meteorites fallen in Earth and within the returned samples of comet $81 \mathrm{P} /$ Wild2 from the Stardust mission (Glavin et al. 2008; Sandford, et al. 2006). From a catalytic point of view, this work also highlights the role of acidic charged species such as the $\mathrm{H}_{3} \mathrm{O}^{+}$ion at the water-ice surfaces, which is essential for the formation of the $\mathrm{NH}_{2}=\mathrm{CH}_{2}{ }^{+}$ species. These theoretical findings are in agreement with the experimental results of Pilling et al. (2010), which revealed the formation of $\mathrm{NH}_{4}^{+}$cations when an $\mathrm{H}_{2} \mathrm{O}: \mathrm{NH}_{3}$ ice was bombarded by highly charged energetic particles at cryogenic temperatures. Based on our results, the presence of $\mathrm{NH}_{4}{ }^{+}$is due to the ionization of the ice, which consequently leads to the formation of $\mathrm{H}_{3} \mathrm{O}^{+}$, which in turn may readily transfer the acidic protons to $\mathrm{NH}_{3}$. In our case, the proton transfer occurs barrierless toward $\mathrm{NH}=\mathrm{CH}_{2}$.

To summarize, a water-dominated ice mantle covering a silicate-based core of an interstellar grain is transformed by the action of ionizing particles such as cosmic rays. Consequently, the water ice becomes ionized and thus the surface $\mathrm{OH}^{\bullet}$ and $\mathrm{H}_{3} \mathrm{O}^{+}$defects are formed. While the former groups are able to react with other species present in the ice (such as $\mathrm{CO}$ ), the $\mathrm{H}_{3} \mathrm{O}^{+}$ions immediately release the acidic protons to basic species available within the ice (in this work to $\mathrm{NH}=\mathrm{CH}_{2}$, but also $\mathrm{NH}_{3}$ and $\mathrm{HCN}$ are suitable candidates). When ice initially contains $\mathrm{CO}$ and $\mathrm{NH}=\mathrm{CH}_{2}$, the formation of glycinerelated species through the mechanisms proposed here become feasible. Obviously, besides this reaction, other process may indeed occur; for instance, in an ice that contains $\mathrm{H}_{2} \mathrm{C}=\mathrm{O}$, the ionization may induce the formation of $\mathrm{H}_{2} \mathrm{C}=\mathrm{OH}^{+}$, which bears a $\mathrm{C}$ atom very prone to react with nucleophile species.

Other potential ways to form the important $\mathrm{H}_{3} \mathrm{O}^{+}$ions within water ices have been described. On one hand, Woon (2011) showed by means of quantum chemical methods that addition of the $\mathrm{HCO}^{+}$and $\mathrm{CH}_{3}{ }^{+}$cation species on a $\left(\mathrm{H}_{2} \mathrm{O}\right)_{17}$ cluster brings about $\mathrm{HCOOH}$ and $\mathrm{CH}_{3} \mathrm{OH}$, with the barrierless formation of $\mathrm{H}_{3} \mathrm{O}^{+}$species. On the other hand, a theoretical work of TorrentSucarrat et al. (2011) showed that the presence of hydroperoxyl radical $\left(\mathrm{HO}_{2}\right)$ at the surface of the $\left(\mathrm{H}_{2} \mathrm{O}\right)_{20}$ and $\left(\mathrm{H}_{2} \mathrm{O}\right)_{21}$ water clusters can induce the water auto-ionization (i.e., $2 \mathrm{H}_{2} \mathrm{O} \rightarrow$ $\mathrm{OH}^{-}+\mathrm{H}_{3} \mathrm{O}^{+}$) followed by a proton transfer from the $\mathrm{HO}_{2}$ to the formed $\mathrm{OH}^{-}$to restore $\mathrm{H}_{2} \mathrm{O}$. These alternative chemical routes to the $\mathrm{H}_{3} \mathrm{O}^{+}$formation are energetically softer compared to cosmic rays impact, and avoid the Coulombic repulsion between multiple ionized species in the same ice particle (Kaiser \& Roessler 1998). In this context, further theoretical investigations focusing on alternative routes toward the $\mathrm{H}_{3} \mathrm{O}^{+}$species in water ices are explored in our laboratory, involving the adsorption of $\mathrm{HO}_{2}$-like interstellar molecules.

A.R. is indebted to MICINN of the Spanish Government for a Juan de la Cierva contract. Financial support from MICINN (project CTQ2011-24847/BQU,) and DIUE (project 2009SGR638), and the use of the Catalonia Supercomputer Centre (CESCA) are gratefully acknowledged. Supplementary data will be provided by the corresponding author upon request.

\section{REFERENCES}

Balucani, N., Asvany, O., Chang, A. H. H., et al. 1999a, J. Chem. Phys., 111,7457

Balucani, N., Asvany, O., Chang, A. H. H., et al. 1999b, J. Chem. Phys., 111,7472

Balucani, N., Asvany, O., Chang, A. H. H., et al. 2000, J. Chem. Phys., 113,8643

Becke, A. D. 1993, J. Chem. Phys., 98, 1372

Belloche, A., Menten, K. M., Comito, C., et al. 2008, A\&A, 482, 179

Bernstein, M. P., Dworkin, J. P., Sandford, S. A., Cooper, G. W., \& Allamandola, L. J. 2002, Nature, 416, 401

Bordwell, F. G., \& Lynch, T. Y. 1989, J. Am. Chem. Soc., 111, 7558

Bossa, J.-B., Duvernay, F., Theulé, P., et al. 2009, A\&A, 506, 601

Courmier, D., Gardebien, F., Minot, C., \& St-Amant, A. 2005, Chem. Phys. Lett., 405, 357

Cronin, J. R., \& Pizzarello, S. 1997, Science, 275, 951

Chen, L., \& Woon, D. E. 2011, J. Phys. Chem. A, 115, 5166

Chyba, C., \& Sagan, C. 1992, Nature, 355, 125

Dickens, J. E., Irvine, W. M., DeVries, C. H., \& Ohishi, M. 1997, ApJ, 479, 307

Ehrenfreund, P., \& Charnley, S. B. 2000, ARA\&A, 38, 427

Ehrenfreund, P., \& Sephton, M. A. 2006, Faraday Discuss., 133, 277

Elsila, J. E., Dworkin, J. P., Bernstein, M. P., Martin, M. P., \& Sandford, S. A. 2007, ApJ, 660, 911

Elsila, J. E., Glavin, D. P., \& Dworkin, J. P. 2009, Meteorit. Planet. Sci., 44, 1323

Ferrari, A. M., Garrone, E., \& Ugliengo, P. 1993, Chem. Phys. Lett., 212, 644

Frisch, M. J., Trucks, G. W., Schlegel, H. B., et al. 2004, GAUSSIAN 03, Revision C.02 (Wallingford, CT: Gaussian Inc.) 
Georgieva, I., Trendafilova, N., Rodríguez-Santiago, L., \& Sodupe, M. 2005, J. Phys. Chem. A, 109, 5668

Glavin, D. P., Dworkin, J. P., \& Sandford, S. A. 2008, Meteorit. Planet. Sci., 43, 399

Herbst, E., \& van Dishoeck, E. F. 2009, ARA\&A, 47, 427

Holtom, P. D., Bennett, C. J., Osamura, Y., Mason, N. J., \& Kaiser, R. I. 2005, ApJ, 626, 940

Huang, L. C. L., Asvany, O., Chang, A. H. H., et al. 2000, J. Chem. Phys., 113, 8656

Hudson, R. L., Moore, M. H., Dworkin, J. P., Martin, M. P., \& Pozun, Z. D. 2008, Astrobiology, 8, 771

Kaiser, R. I., \& Roessler, K. 1998, ApJ, 503, 959

Kayi, H., Kaiser, R. I., \& Head, J. D. 2011, Phys. Chem. Chem. Phys., 13, 11083 Knowles, D. J., Wang, T., \& Bowie, J. H. 2010, Org. Biomol. Chem., 8, 4934

Kobayashi, K., Kasamatsu, T., Kaneko, T., et al. 1995, Adv. Space Res., 16, 21

Koch, D. M., Toubin, C., Peslherbe, G. H., \& Hynes, J. T. 2008, J. Phys. Chem. C, 112,2972

Koch, W., \& Holthausen, M. C. 2001, A Chemist's Guide to Density Functional Theory (2nd ed.; Weinheim: Wiley-VCH)

Lafosse, A., Bertin, M., Domaracka, A., Pliszka, D., Illenberger, E., \& Azria, R. 2006, Phys. Chem. Chem. Phys., 8, 5564

Lee, C.-W., Kim, J.-K., Moon, E.-S., Minh, Y. C., \& Kang, H. 2009, ApJ, 697, 428

Lee, C.-W., Yang, W., \& Parr, R. G. 1988, Phys. Rev. B, 37, 785

Maeda, S., \& Ohno, K. 2006, ApJ, 640, 823

Maheshwary, S., Patel, N., Sathyamurthy, N., Kulkarni, A. D., \& Gadre, S. R. 2001, J. Phys. Chem. A, 105, 10525

McQuarrie, D. 1986, Statistical Mechanics (New York: Harper and Row)

Muñoz Caro, G. M., Meierhenrich, U. J., Schutte, W. A., et al. 2002, Nature, 416, 403

Nuevo, M., Auger, G., Blanot, D., \& d'Hendecourt, L. 2008, Origins Life Evol. Biosphere, 38, 37
Oró, J. 1961, Nature, 190, 389

Pilling, S., Seperuelo Duarte, E., da Silveira, E. F., et al. 2010, A\&A, 509, A87

Pizzarello, S. 2006, Acc. Chem. Res., 39, 231

Pizzarello, S., Huang, Y., \& Alexandre, M. R. 2008, Proc. Natl. Acad. Sci. U. S. A., 105, 3700

Poater, J., Solà, M., Rimola, A., Rodríguez-Santiago, L., \& Sodupe, M. 2004, J. Phys. Chem. A, 108, 6072

Rimola, A., Rodríguez-Santiago, L., \& Sodupe, M. 2006, J. Phys. Chem. B, 110, 24189

Rimola, A., Sodupe, M., \& Ugliengo, P. 2010, Phys. Chem. Chem. Phys., 12, 5285

Sandford, S. A., Aléon, J., Alexander, C. M. O.'D., et al. 2006, Science, 314 1720

Sholl, D., \& Steckel, J. A. 2009, Density Functional Theory: A Practical Introduction (Hoboken, NJ: Wiley)

Simon, S., Sodupe, M., \& Bertran, J. 2002, J. Phys. Chem. A, 106, 5697

Sodupe, M., Bertran, J., Rodríguez-Santiago, L., \& Baerends, E. J. 1999, J. Phys. Chem. A, 103, 166

Sousa, S. F., Fernandes, P. A., \& Ramos, M. J. 2007, J. Phys. Chem. A, 111, 10439

Takano, Y., Masuda, H., Kaneko, T., \& Kobayashi, K. 2002, Chem. Lett., 31 986

Torrent-Sucarrat, M., Ruiz-Lopez, M. F., Martins-Costa, M., Francisco, J. S., \& Anglada, J. M. 2011, Chem. Eur. J., 17, 5076

Ugalde, J. M., Alkorta, I., \& Elguero, J. 2000, Angew. Chem. Int. Ed., 39, 717

van Dishoeck, E. F. 1998, Faraday Discuss., 109, 31

van Dishoeck, E. F. 2004, ARA\&A, 42, 119

Woon, D. E. 2001, J. Phys. Chem. A, 105, 9478

Woon, D. E. 2002, ApJ, 571, L177

Woon, D. E. 2011, ApJ, 728, 44

Yu, D., Rauk, A., \& Armstrong, D. A. 1995, J. Am. Chem. Soc., 117, 1789 